\title{
NOTES
}

\section{Molecular Interaction Studies on Poly(vinyl chloride) in Chlorobenzene by Acoustic Method}

\author{
B. Sundaresan and A. Srinivasa RaO \\ Raman School of Physics, Pondicherry University, \\ Kalapet, Pondicherry-605 014, India
}

(Received November 29, 1993)

\begin{abstract}
KEY WORDS Ultrasonic Velocity / Intermolecular Interaction / Rao's Number / Poly(vinyl chloride) / Chlorobenzene / van der Waals' Bond /
\end{abstract}

A review of literature ${ }^{1-5}$ on the acoustical studies in polymer solutions reveals that ultrasonic velocity measurements are useful to understand the nature of molecular interactions in these systems. As poly(vinyl chloride) (PVC) is an industrially important polymer, it is decided to study the molecular interactions of solutions of PVC in chlorobenzene (CB) by measuring the ultrasonic velocity in the system. In order to observe the influence of heat on molecular interactions of the present system, experiments were carried out at different temperatures. Shear viscosities and densities were measured in the above solutions and the results are presented in this note. The polymer, PVC, with a characteristic constant $K$ of $60-65$ was obtained from Central Institute of Plastics and Engineering Technology (CIPET), Madras, India and used after standard purification. ${ }^{6} \mathrm{AR} / \mathrm{BDH}$ grade solvent, $\mathrm{CB}$ was also purified using standard techniques. ${ }^{7} \mathrm{Un}$ saturation of PVC due to the presence of its monomer vinyl chloride was eliminated during purification.

The molecular weight of PVC, determined using the viscometric method, ${ }^{8}$ was around 125000. From elemental analysis, ${ }^{9}$ the chlorine content of the polymer PVC used in this study was $56.72 \%$. PVC was dissolved in solvent CB by moderate stirring at solute concentrations from $0.125 \%$ to $3 \%$ by weight. Precautions were undertaken to avoid various types of degradation ${ }^{10,11}$ of the polymer in solution.

Ultrasonic velocities in the polymer solutions were measured to an accuracy of $\pm 0.05 \%$ using a multifrequency continuous wave ultrasonic interferometer (Model M81, Mittel Enterprises, New Delhi) at an RF frequency of $2 \mathrm{MHz}$ at $303 \mathrm{~K}, 313 \mathrm{~K}$, and $323 \mathrm{~K}$. The temperature of the sample cell was maintained constant by circulating water from a thermostatically controlled water bath with an accuracy of $\pm 0.1^{\circ} \mathrm{C}$.

Density $(\rho)$ was measured to an accuracy of \pm 3 parts in $10^{3}$ using a dilatometer at different temperatures $303 \mathrm{~K}, 313 \mathrm{~K}$, and $323 \mathrm{~K}$. The shear viscosities $\left(\eta_{\mathrm{s}}\right)$ of the solutions were measured to an accuracy of $1 \%$ using an Ostwald's viscometer at $303 \mathrm{~K}, 313 \mathrm{~K}$, and $323 \mathrm{~K}$ by immersing the viscometer in the thermostatically controlled water bath. The measured values of ultrasonic velocity, density and viscosity for the solute concentrations from $0.125 \%$ to $3 \%$ at the temperatures $303 \mathrm{~K}$, $313 \mathrm{~K}$, and $323 \mathrm{~K}$ and calculated ultrasonic parameters, namely adiabatic compressibility $\left(\beta_{\mathrm{s}}\right)$, intermolecular freelength $\left(L_{f}\right)$ and Rao's number $(R)$ are given in Tables I to III. Adiabatic compressibility was calculated using the formula $\beta_{\mathrm{s}}=\left(c^{2} \rho\right)^{-1}$, where $\rho$ is the density 
Table I. Ultrasonic velocity and related parameters for a solution of PVC in chlorobenzene at $303 \mathrm{~K}^{\mathrm{a}}$

\begin{tabular}{|c|c|c|c|c|c|c|}
\hline \multirow{2}{*}{$X$} & $\rho$ & $c$ & $\beta_{\mathrm{s}} \times 10^{-10}$ & $\eta_{\mathrm{s}} \times 10^{-3}$ & $L_{\mathrm{f}}$ & \multirow{2}{*}{$R$} \\
\hline & $\mathrm{kg} \mathrm{m}^{-3}$ & $\mathrm{~ms}^{-1}$ & $\mathrm{~N}^{-1} \mathrm{~m}^{2}$ & $\mathrm{Ns} \mathrm{m}^{-2}$ & $\AA$ & \\
\hline 0.000 & 1108.01 & 1234 & 5.9269 & 0.7220 & 0.4858 & 1207.59 \\
\hline 0.125 & 1109.35 & 1237 & 5.8910 & 0.7879 & 0.4843 & 1207.10 \\
\hline 0.250 & 1110.69 & 1238.2 & 5.8725 & 0.8781 & 0.4835 & 1206.03 \\
\hline 0.500 & 1111.59 & 1239.4 & 5.8564 & 1.1302 & 0.4829 & 1205.44 \\
\hline 0.750 & 1116.06 & 1241 & 5.8179 & 1.4856 & 0.4813 & 1201.65 \\
\hline 1.000 & 1116.51 & 1242.2 & 5.8044 & 1.9278 & 0.4807 & 1201.04 \\
\hline 2.000 & 1116.96 & 1242 & 5.8040 & 5.2990 & 0.4807 & 1200.49 \\
\hline 3.000 & 1117.40 & 1244 & 5.7830 & 14.1101 & 0.4899 & 1200.66 \\
\hline
\end{tabular}

a $X$, concentration in weight percent; $\rho$, density of solution; $c$, ultrasonic velocity; $\beta_{\mathrm{s}}$, adiabatic compressibility; $\eta_{\mathrm{s}}$, shear viscosity; $L_{\mathrm{f}}$, free length; $R$, Rao's number.

Table II. Ultrasonic velocity and related parameters for a solution of PVC in chlorobenzene at $313 \mathrm{~K}^{\mathrm{a}}$

\begin{tabular}{|c|c|c|c|c|c|c|}
\hline \multirow{2}{*}{$X$} & $\rho$ & $c$ & $\beta_{\mathrm{s}} \times 10^{-10}$ & $\eta_{\mathrm{s}} \times 10^{-3}$ & $L_{\mathrm{f}}$ & \multirow{2}{*}{$R$} \\
\hline & $\mathrm{kg} \mathrm{m}^{-3}$ & $\mathrm{~ms}^{-1}$ & $\mathrm{~N}^{-1} \mathrm{~m}^{2}$ & $\mathrm{Ns} \mathrm{m}^{-2}$ & $\AA$ & \\
\hline 0.000 & 1105.40 & 1211 & 6.1687 & 0.6039 & 0.5042 & 1202.87 \\
\hline 0.125 & 1107.83 & 1211.2 & 6.1531 & 0.6958 & 0.5036 & 1200.30 \\
\hline 0.250 & 1109.19 & 1212.1 & 6.1364 & 0.8007 & 0.5029 & 1199.12 \\
\hline 0.500 & 1110.12 & 1213 & 6.1222 & 1.0151 & 0.5023 & 1198.41 \\
\hline 0.750 & 1113.27 & 1214.5 & 6.0898 & 1.3000 & 0.5009 & 1195.52 \\
\hline 1.000 & 1114.51 & 1216 & 6.0680 & 1.6715 & 0.5001 & 1194.68 \\
\hline 2.000 & 1115.15 & 1220 & 6.0249 & 4.7280 & 0.4983 & 1195.30 \\
\hline 3.000 & 1116.36 & 1215 & 6.0680 & 12.9152 & 0.5001 & 1192.37 \\
\hline
\end{tabular}

a $X$, concentration in weight percent; $\rho$, density of solution; $c$, ultrasonic velocity; $\beta_{\mathrm{s}}$, adiabatic compressibility; $\eta_{\mathrm{s}}$, shear viscosity; $L_{\mathrm{f}}$, free length; $R$, Rao's number.

Table III. Ultrasonic velocity and related parameters for a solution of PVC in chlorobenzene at $323 \mathrm{~K}^{\mathrm{a}}$

\begin{tabular}{|c|c|c|c|c|c|c|}
\hline \multirow{2}{*}{$X$} & $\rho$ & $c$ & $\beta_{\mathrm{s}} \times 10^{-10}$ & $\eta_{\mathrm{s}} \times 10^{-3}$ & $L_{\mathrm{f}}$ & \multirow{2}{*}{$R$} \\
\hline & $\mathrm{kg} \mathrm{m}^{-3}$ & $\mathrm{~ms}^{-1}$ & $\mathrm{~N}^{-1} \mathrm{~m}^{2}$ & $\mathrm{Ns} \mathrm{m}^{-2}$ & $\AA$ & \\
\hline 0.000 & 1103.22 & 1173 & 6.5878 & 0.5280 & 0.5300 & 1192.51 \\
\hline 0.125 & 1105.69 & 1173 & 6.5731 & 0.6131 & 0.5294 & 1189.84 \\
\hline 0.250 & 1108.14 & 1173.2 & 6.5563 & 0.7199 & 0.5287 & 1187.28 \\
\hline 0.500 & 1109.05 & 1173 & 6.5532 & 0.9102 & 0.5286 & 1186.24 \\
\hline 0.750 & 1111.96 & 1192.4 & 6.3251 & 1.1829 & 0.5193 & 1189.61 \\
\hline 1.000 & 1113.23 & 1205.4 & 6.1823 & 1.5046 & 0.5134 & 1192.56 \\
\hline 2.000 & 1114.41 & 1202 & 6.2108 & 4.3370 & 0.5146 & 1190.18 \\
\hline 3.000 & 1115.26 & 1194 & 6.2895 & 11.7791 & 0.5179 & 1186.63 \\
\hline
\end{tabular}

a $X$, concentration in weight percent; $\rho$, density of solution; $c$, ultrasonic velocity; $\beta_{\mathrm{s}}$, adiabatic compressibility; $\eta_{\mathrm{s}}$, shear viscosity; $L_{\mathrm{f}}$, free length; $R$, Rao's number. 


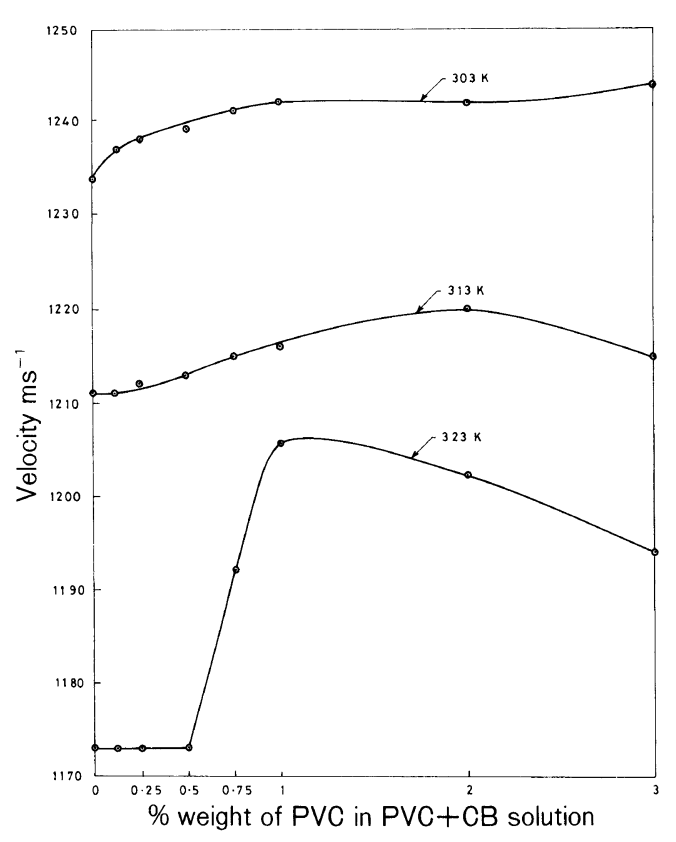

Figure 1. Variation of ultrasonic velocity with concentration of PVC in PVC + CB solution.

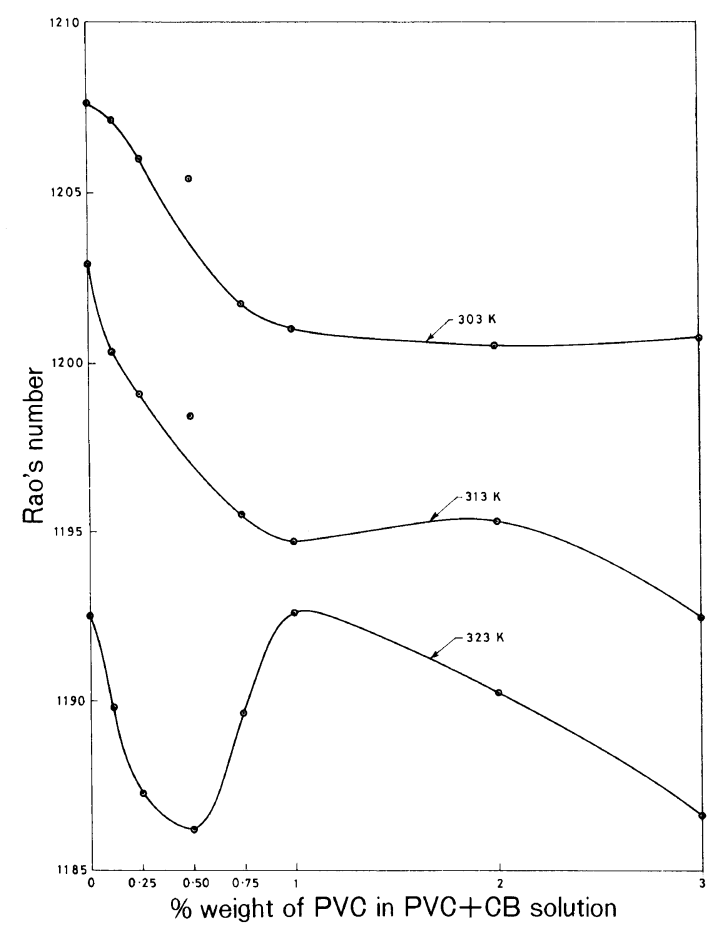

Figure 2. Variation of Rao's number with concentration of PVC in PVC + CB solution. of solution and $c$ is the ultrasonic velocity in the solution. The intermolecular freelength was calculated as $L_{\mathrm{f}}=k\left(\beta_{\mathrm{s}}\right)^{1 / 3}$, where $k$ is a constant and $k$ for different temperatures were taken from the literature. ${ }^{12,13}$ Rao's number was calculated using the formula $c^{1 / 2} V=R$, where $c$ is the ultrasonic velocity and $V$ is the molar volume of the solution. Variation of the ultrasonic velocity and Rao's constant with the concentration of PVC in $\mathrm{CB}$ at different temperatures are graphically represented in Figures 1 and 2.

At $303 \mathrm{~K}$, it may be seen from Figure 1 that ultrasonic velocity slightly increases with PVC concentration from $1234 \mathrm{~m} \mathrm{~s}^{-1}$ of pure solvent to $1244 \mathrm{~m} \mathrm{~s}^{-1}$ at $3 \%$. At an elevated temperature of $313 \mathrm{~K}$, ultrasonic velocity increases slightly with solute concentration from 1211 $\mathrm{m} \mathrm{s}^{-1}$ of pure solvent to $1220 \mathrm{~m} \mathrm{~s}^{-1}$ at $2 \%$ and ultrasonic velocity decreases to $1215 \mathrm{~m} \mathrm{~s}^{-1}$ at $3 \%$. At $323 \mathrm{~K}$, ultrasonic velocity remains constant as $1173 \mathrm{~m} \mathrm{~s}^{-1}$ for solute-PVC concentrations from $0.125 \%$ to $0.5 \%$. For solute concentration above $0.5 \%$, the ultrasonic velocity increases suddenly to $1192.4 \mathrm{~m} \mathrm{~s}^{-1}$ at $0.75 \%$ and further increases to $1205.4 \mathrm{~m} \mathrm{~s}^{-1}$ at $1 \%$. For solute concentrations above $1 \%$, the ultrasonic velocity decreases with increase of solute concentration to $1194 \mathrm{~m} \mathrm{~s}^{-1}$ at $3 \%$.

The values of adiabatic compressibility and freelength show inverted behaviour of ultrasonic velocity with increase of solute concentration at any temperature. Densities and viscosities increase with solute concentration for any temperature and generally decrease with increase in temperature for any solute concentration.

The gradual increase in ultrasonic velocity with solute concentration at $303 \mathrm{~K}$ may be due to the association between the solute molecules and solvent molecules, i.e., PVC and CB. As concentration increases, one macromolecule may influence another indirectly by mutual interactions with other molecules. When these molecules are of the solvent, the phenomenon is referred to as hydrodynamic screening and 
significantly determines the viscous flow properties of rather dilute polymer solutions. Alternatively, in more concentrated solutions and bulk polymers, direct segment to segment interactions occur. ${ }^{14}$ They cause association between the PVC and CB molecules and this may be responsible for the increase in ultrasonic velocity. Such an effect has been reported for PVC in Tetrahydrofuran. ${ }^{1}$

At high solute concentrations, polymer chains interweave and centres are formed owing to strong van der Waals' polar bonds or hydrogen bonds. Temporary van der Waals' bonds in a polymer lattice are formed and disrupted at higher temperatures due to thermal motion. ${ }^{15}$ At $313 \mathrm{~K}$, ultrasonic velocity increases gradually with increase of solute concentration from $0.125 \%$ to $2 \%$ and decreases with further increase to $3 \%$. At $323 \mathrm{~K}$, variation of ultrasonic velocity with solute concentration is similar to that at $313 \mathrm{~K}$ with the exception that decrease of ultrasonic velocity occurs at a lower solute concentration of $1 \%$. This variation in ultrasonic velocity at these temperatures may be due to the formation and disruption of van der Waals' polar centres in the polymer lattice due to thermal motion of PVC macromolecules.

The increase in ultrasonic velocity at a temperature of $303 \mathrm{~K}$ is $10 \mathrm{~m} \mathrm{~s}^{-1}$ in the range of $0 \%$ to $3 \%$ solute concentration and at $313 \mathrm{~K}$, it is $9 \mathrm{~m} \mathrm{~s}^{-1}$ in the range of $0 \%$ to $2 \%$ solute concentration. At $323 \mathrm{~K}$, the increase in ultrasonic velocity is $32.4 \mathrm{~m} \mathrm{~s}^{-1}$ for increase in solute concentration from the pure solvent to $1 \%$. The decrease in ultrasonic velocity at $313 \mathrm{~K}$ is $5 \mathrm{~m} \mathrm{~s}^{-1}$ in the solute concentration range of $2 \%$ to $3 \%$ and at $323 \mathrm{~K}$ it is $11.4 \mathrm{~m} \mathrm{~s}^{-1}$ in the range of $1 \%$ to $3 \%$. The increase in ultrasonic velocity is fairly high only at $323 \mathrm{~K}$ in the solute concentration range of 0.5 to $1 \%$ in the present study. This shows that interactions between solute and solvent molecules are significant at $323 \mathrm{~K}$ in the above solute concentration ranges. However, for any solute concentration, ultrasonic velocity decreases with increase of temperature due to weakening of intermolecular force. The increase in ultrasonic velocity in the above solute concentration ranges at $323 \mathrm{~K}$ may be due to increase in mobility of the molecules which may lead to increased cohesion between molecules filling all available free spaces. At a higher concentration range of 1 to $3 \%$, at $323 \mathrm{~K}$, decrease in ultrasonic velocity may be due to weakening of intermolecular force. This may be due to nonavailability of free space which reduces the mobility of molecules. Further ultrasonic velocity studies at still higher temperatures are necessary in this system to understand clearly the influence of temperature on molecular interactions in these solutions.

The decrease in ultrasonic velocity with increase of temperature in binary system is a general trend in associated organic liquids and can be determined from Rao's constant at various temperatures. Rao's number is independent of temperature for unassociated organic liquids. ${ }^{16}$ If variation of $R$ with the concentration of one of the components is non-linear, this generally indicates strong association between molecules. ${ }^{17}$ It can be seen from Figure 2 that the calculated values of Rao's number for this system depend upon temperature and vary non-linearly with the concentration of PVC in CB which confirms interactions between molecules PVC and CB. Variation in adiabatic compressibility and freelength with increase of solute concentration further confirms interactions in the system. Variation of viscosity and density with temperature usually confirms the above conclusions. Further ultrasound absorption study will throw more light on structural aspects of the present system.

Acknowledgment. One of the authors (BS) is grateful to the University Grants Commission, New Delhi, for financial assistance provided through the project "Ultrasonic Investigations of Polymers as Bio-materials". 


\section{REFERENCES}

1. S. K. Hassun, S. H. F. Al-Madfai, and M. M. F. Al-Jarrah, Br. Polym. J., 17, 330 (1985).

2. S. Bagchi, S. K. Nema, and R. P. Singh, Eur. Polym. J., 22, 851 (1986).

3. R. A. Pethrick and B. T. Poh, Br. Polym. J., 15, 149 (1983).

4. B. Saraf and K. Samal, Acustica, 55, 60 (1984).

5. R. P. Singh, G. V. Reddy, Acustica, 46, 342 (1980).

6. Kirk-Othmer, "Encylopedia of Chemical Technology," Vol. 18, 3rd ed, John Wiley \& Sons, New York, N.Y., 1982, pp $214-216$.

7. B. S. Furniss, A. J. Hannaford, V. Rogers, P. W. G. Smith, and A. R. Tatchell, "Vogel's Textbook of Practical Organic Chemistry," 4th ed, English Language Book Society, Longman, Essex, 1986, pp $146-155$.

8. F. W. Billmeyer, Jr., "Text Book of Polymer Science," 3rd ed, John Wiley \& Sons, New York, N.Y., 1984, pp 208-212.

9. R. T. Morrison and R. N. Boyd, "Organic Chemistry," 4th ed, Allyn and Bacon Inc., London, 1985, pp 73-74.

10. F. W. Billmeyer, Jr, "Text Book of Polymer Science," 3rd ed, John Wiley \& Sons, New York, N.Y., 1984, pp 142-143, 404.

11. V. R. Gowraiker, N. V. Viswanathan, and J. Sreedhar, "Polymer Science," Wiley Eastern Limited, New Delhi, 1988, pp 263-291.

12. B. Jacobson, Acta Chem. Scand., 6, 1485 (1952).

13. B. Jacobson, Acta Chem. Scand., 5, 1214 (1951).

14. W. Bell, A. M. North, R. A. Pethrick, and Jl. Teik, Chem. Soc. Faraday Trans., 2, 75, 1115 (1979).

15. I. G. Mikailov, Ultrasonics, 203 (1964).

16. G. V. Reddy, S. Majumdar, R. P. Singh, Acustica, 47, 343 (1981).

17. P. Vigourex, "Ultrasonics," Chapman and Hall, London, 1952. 